\title{
Structural and Electronic Effects of X-ray Irradiation on Prototypical $[\mathrm{M}(\mathrm{COD}) \mathrm{Cl}]_{2}$ Catalysts
}

\section{Supplementary Information}

Nathalie K. Fernando, ${ }^{\dagger}$ Andrew B. Cairns, ${ }^{\ddagger}$ Claire A. Murray, ${ }^{\top}$ Amber L.

Thompson, ${ }^{\S}$ Joshua L. Dickerson," Elspeth F. Garman, ${ }^{\perp}$ Nayera Ahmed, ${ }^{\dagger}$ Laura E. Ratcliff, $\ddagger$ and Anna Regoutz ${ }^{* \dagger}$

†Department of Chemistry, University College London, 20 Gordon Street, London WC1H OAJ, U.K.

$\ddagger$ Department of Materials, Royal School of Mines, Imperial College London, Exhibition Road, London SW7 2AZ, U.K.

IDiamond Light Source Ltd, Diamond House, Harwell Science and Innovation Campus, Didcot, Oxfordshire OX11 ODE, U.K.

$\S$ Chemical Crystallography, Chemistry Research Laboratory, University of Oxford, South Parks Road, Oxford OX1 3QR, U.K.

\|MRC Laboratory of Molecular Biology, Cambridge Biomedical Campus, Francis Crick Avenue, Cambridge CB2 0QH, U.K.

$\perp$ Department of Biochemistry, University of Oxford, South Parks Road, Oxford OX1 3QU, U.K.

E-mail: a.regoutz@ucl.ac.uk 


\section{Single Crystal X-ray Diffraction}

The Olex2 software was used to carry out a structure solution of single crystal X-ray diffraction $(\mathrm{SCXRD})$ data of $[\operatorname{Ir}(\mathrm{COD}) \mathrm{Cl}]_{2}$ and $[\mathrm{Rh}(\mathrm{COD}) \mathrm{Cl}]_{2}$ with the olex2.solve program and refined with the olex2.refine refinement package. ${ }^{\mathrm{S} 1, \mathrm{~S} 2}$ For $[\operatorname{Ir}(\mathrm{COD}) \mathrm{Cl}]_{2}$, there were 2917 unique reflections $\left(\mathrm{R}_{\text {int }}=0.0447, \mathrm{R}_{\sigma}=0.0238\right)$, which were used in all calculations. The goodness-of-fit on $F^{2}$ was 0.953 . Similarly for $[\mathrm{Rh}(\mathrm{COD}) \mathrm{Cl}]_{2}, 2651$ unique reflections were found, with $\mathrm{R}_{\text {int }}=0.0472, \mathrm{R}_{\sigma}=0.0358$, and a goodness-of-fit on $F^{2}$ of 1.174 . All nonhydrogen atoms were refined anisotropically and hydrogen atoms were located and refined isotropically using a riding model. 


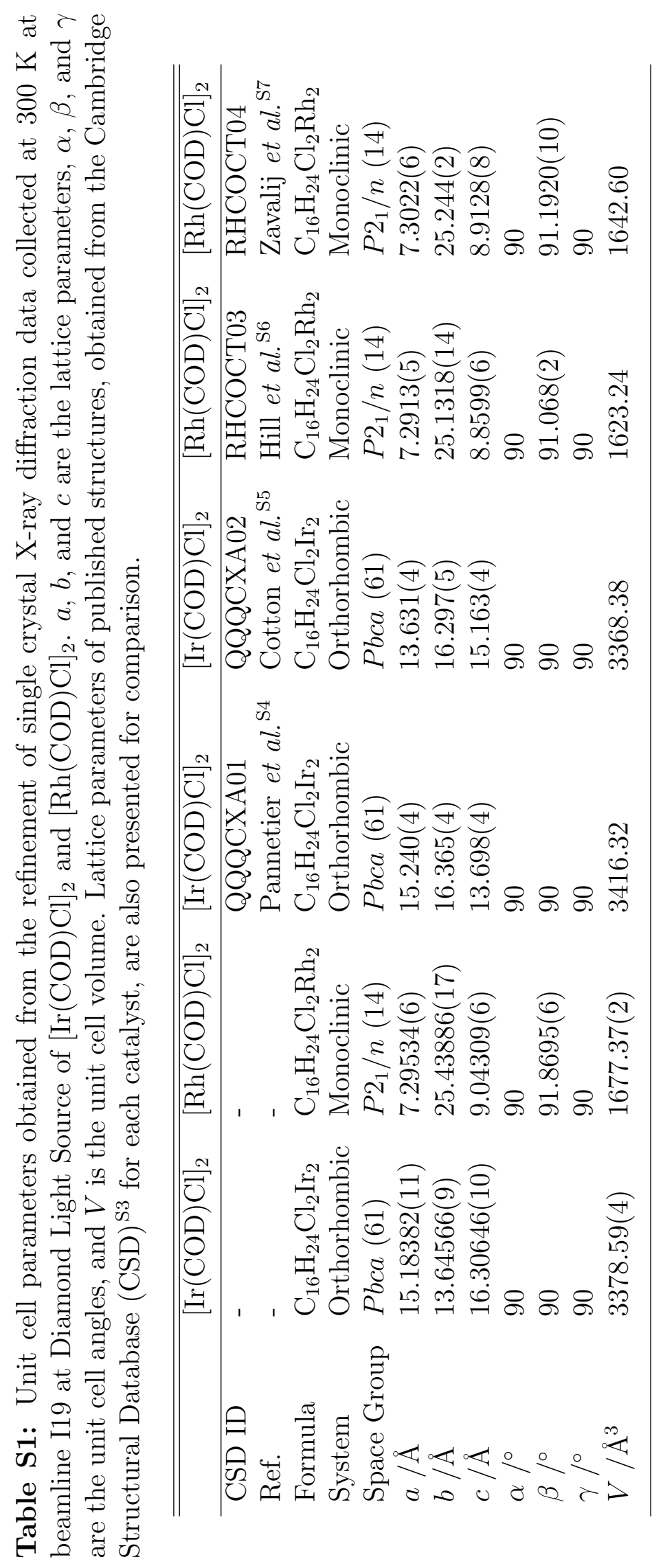




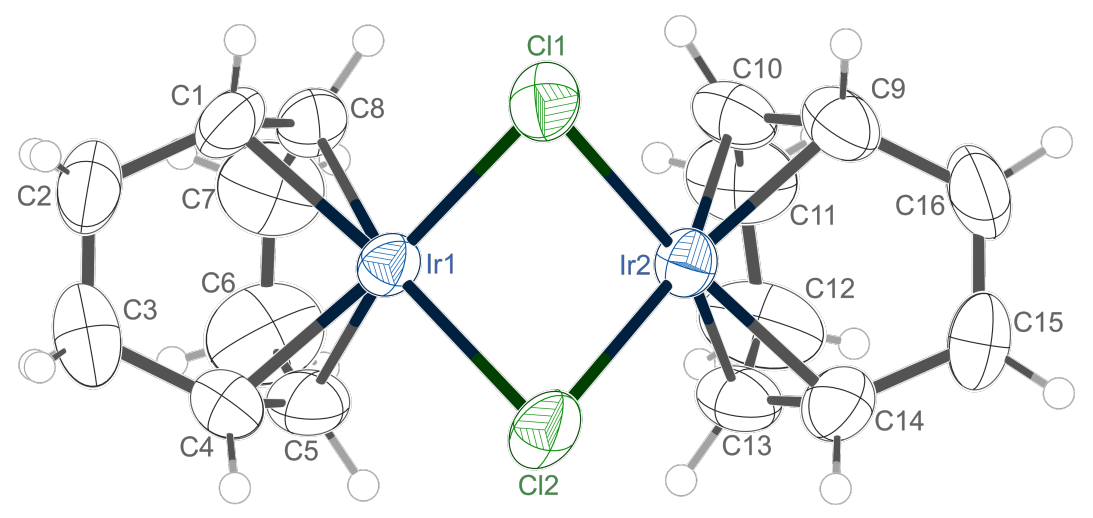

Figure S1: ORTEP view of the $[\operatorname{Ir}(\mathrm{COD}) \mathrm{Cl}]_{2}$ isolated molecule, obtained from structure solution of single crystal XRD measurements collected at $300 \mathrm{~K}$.

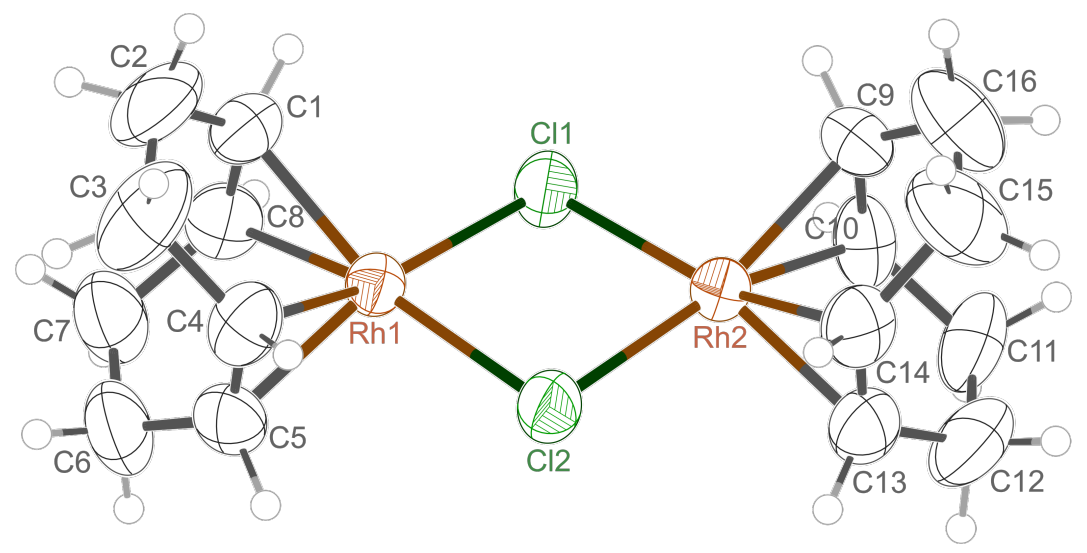

Figure S2: ORTEP view of the $[\mathrm{Rh}(\mathrm{COD}) \mathrm{Cl}]_{2}$ isolated molecule, obtained from structure solution of single crystal XRD measurements collected at $300 \mathrm{~K}$. 

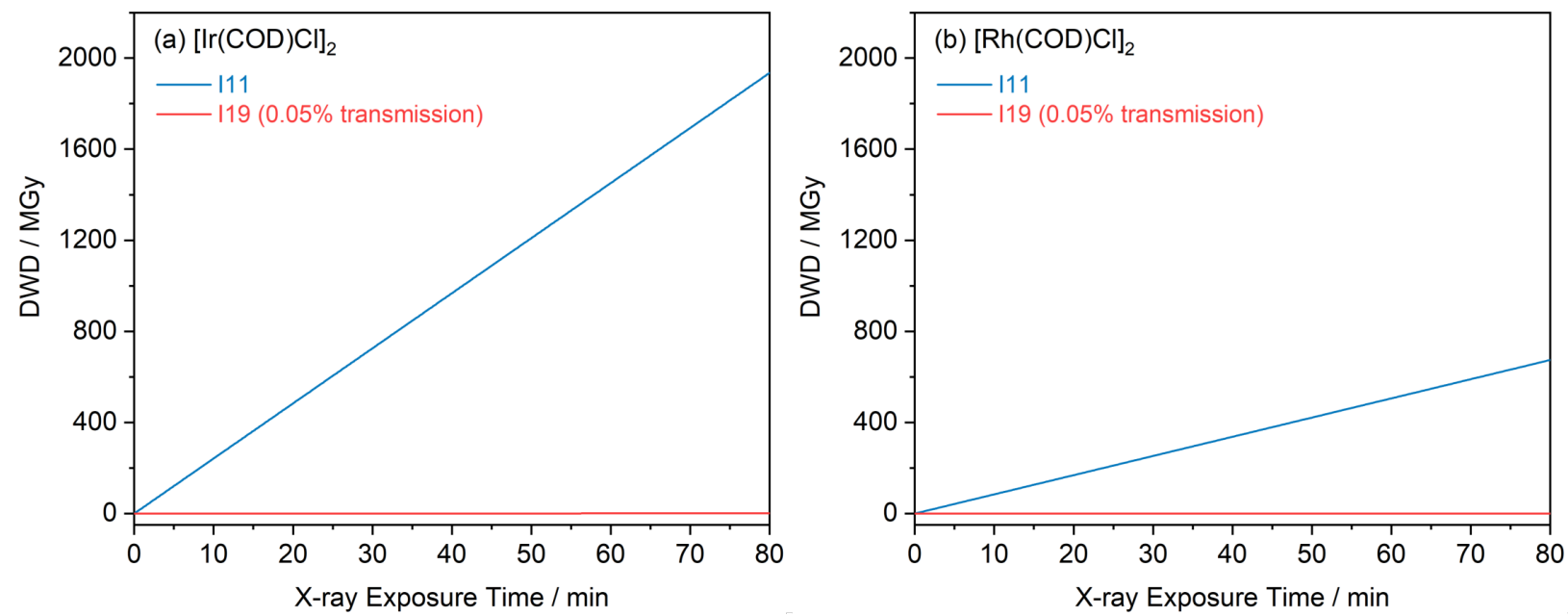

Figure S3: Diffraction Weighted Dose (DWD) obtained using the RADDOSE-3D utility for PXRD at beamline I11 and for the SXRD at beamline I19 at Diamond Light Source with a transmission of $0.05 \%$ for (a) $[\operatorname{Ir}(\mathrm{COD}) \mathrm{Cl}]_{2}$ and (b) $[\mathrm{Rh}(\mathrm{COD}) \mathrm{Cl}]_{2}$. 


\section{Powder X-ray Diffraction}

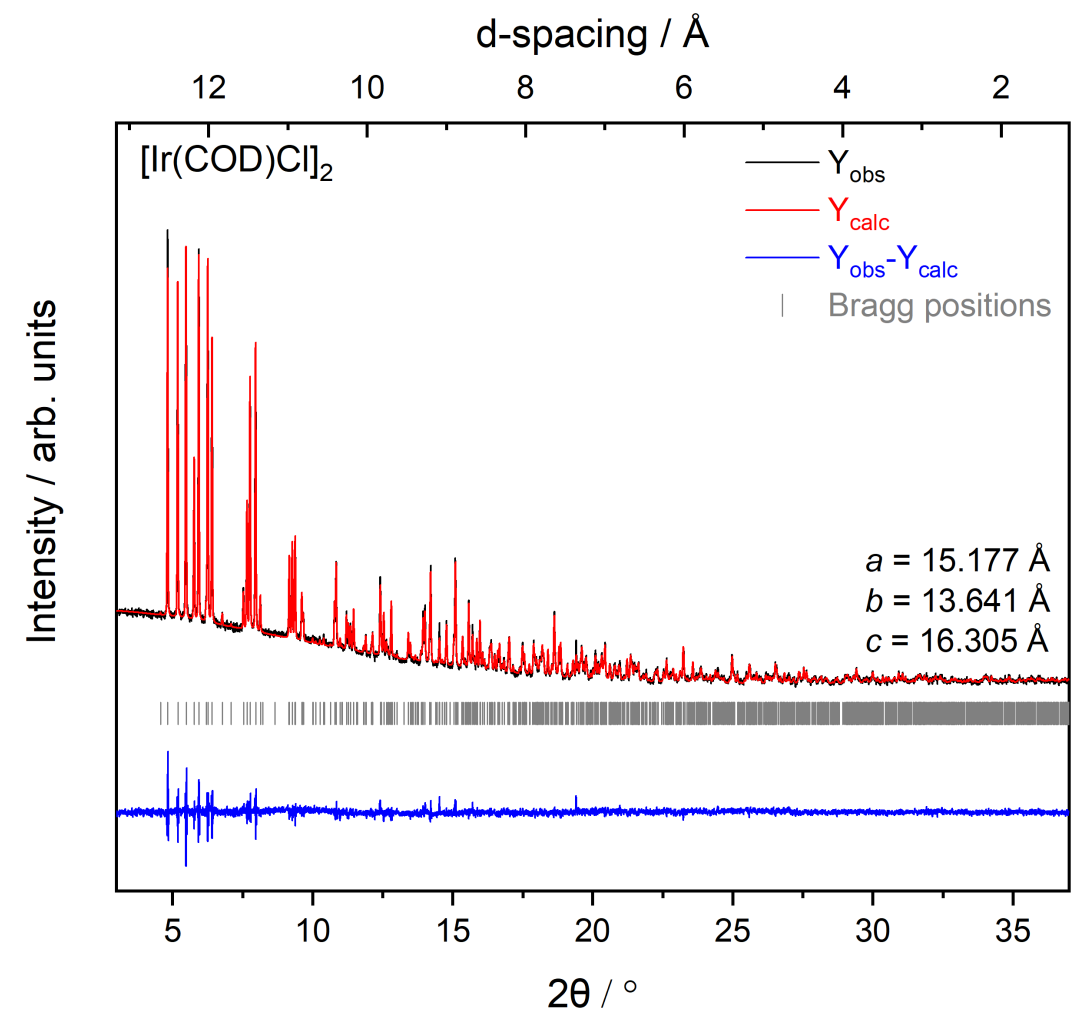

Figure S4: Rietveld refinement of $\mathrm{Pbca}[\mathrm{Ir}(\mathrm{COD}) \mathrm{Cl}]_{2}$ from the first PXRD pattern obtained at a dose of $5.8 \mathrm{MGy}(\mathrm{t}=14 \mathrm{~s})$. Measurements were taken at beamline I11, Diamond Light Source, at $18 \mathrm{keV}$ photon energy and $300 \mathrm{~K}$. 


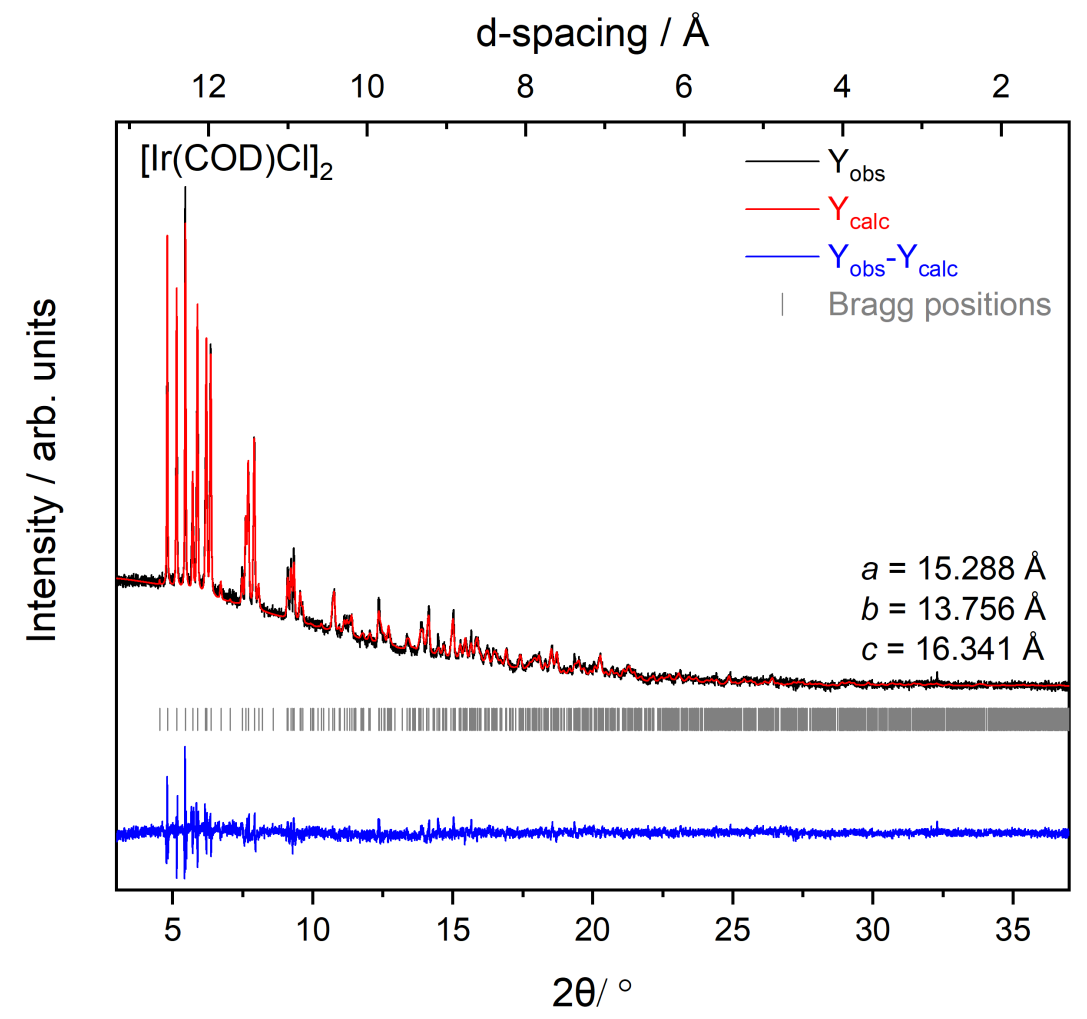

Figure S5: Rietveld refinement of $\mathrm{Pbca}[\mathrm{Ir}(\mathrm{COD}) \mathrm{Cl}]_{2}$ from the final PXRD pattern obtained at an absorbed dose of 2903 MGy $(t=2 \mathrm{~h})$. Measurements were taken at beamline I11, Diamond Light Source, at $18 \mathrm{keV}$ photon energy and $300 \mathrm{~K}$. 


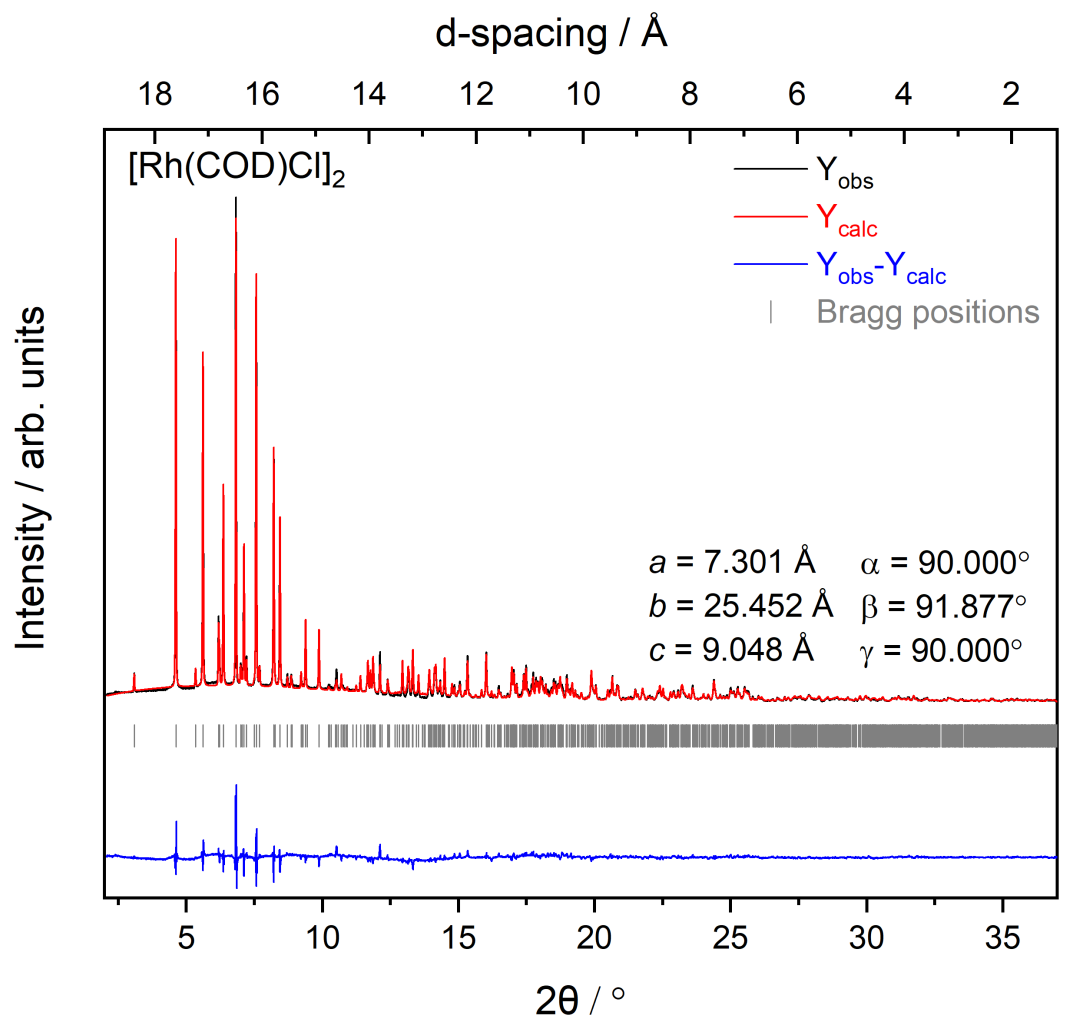

Figure S6: Rietveld refinement of $P 2_{1} / n[\mathrm{Rh}(\mathrm{COD}) \mathrm{Cl}]_{2}$ from the first PXRD pattern obtained at a dose of 2.0 MGy $(\mathrm{t}=14 \mathrm{~s})$. Measurements were taken at beamline I11, Diamond Light Source at $18 \mathrm{keV}$ photon energy and $300 \mathrm{~K}$. 


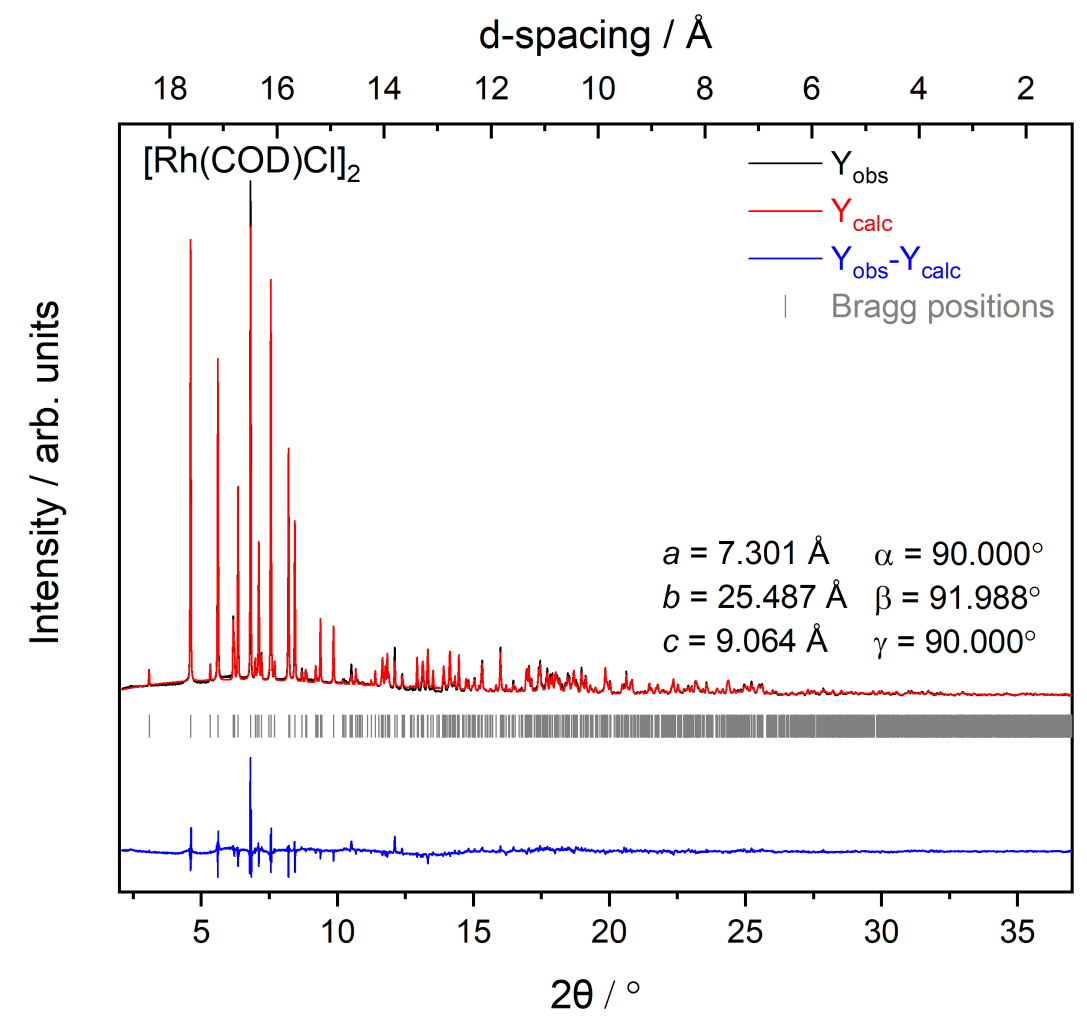

Figure S7: Rietveld refinement of $P 2_{1} / n[\mathrm{Rh}(\mathrm{COD}) \mathrm{Cl}]_{2}$ from the final PXRD pattern obtained at an absorbed dose of $1012 \mathrm{MGy}(\mathrm{t}=2 \mathrm{~h})$. Measurements were taken at beamline I11, Diamond Light Source at $18 \mathrm{keV}$ photon energy and $300 \mathrm{~K}$. 


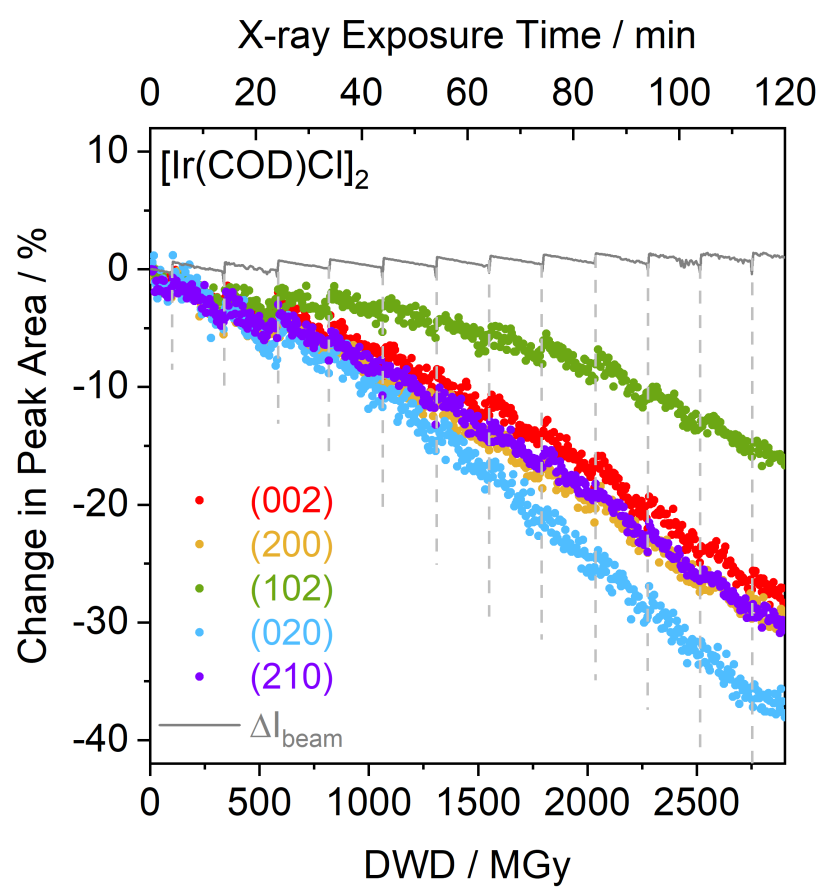

Figure S8: The percentage change in peak area of five low angle Bragg peaks of $[\operatorname{Ir}(\mathrm{COD}) \mathrm{Cl}]_{2}$ obtained from iterative Le Bail refinements with increasing absorbed dose up to 2903 MGy, over the $2 \mathrm{~h}$ measurement period. The plot is adapted from Fig. 3(a) of the main paper to show how the observed discontinuities match the regular drops in beam intensity, $\Delta \mathrm{I}$, due to the topping up of the storage ring. 


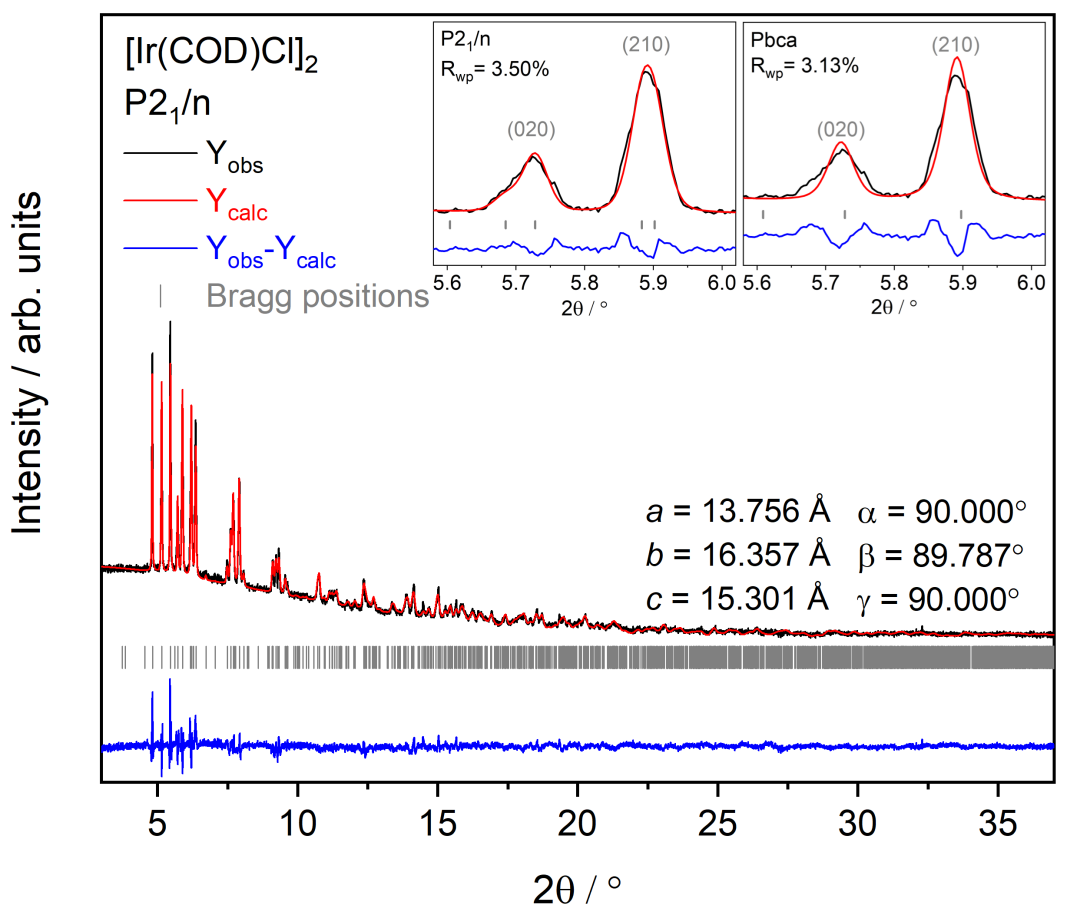

Figure S9: Rietveld refinement of the Ir catalyst from the final PXRD pattern, in which the space group was allowed to transition into the monoclinic $\mathrm{P} 2_{1} / \mathrm{n}$ from its original orthorhombic phase, with a $\mathrm{R}_{\mathrm{wp}}$ of $3.50 \%$. The insets show the fits of the (020) and (210) peaks in the monoclinic phase (left) and the orthorhombic phase (right), for comparison.

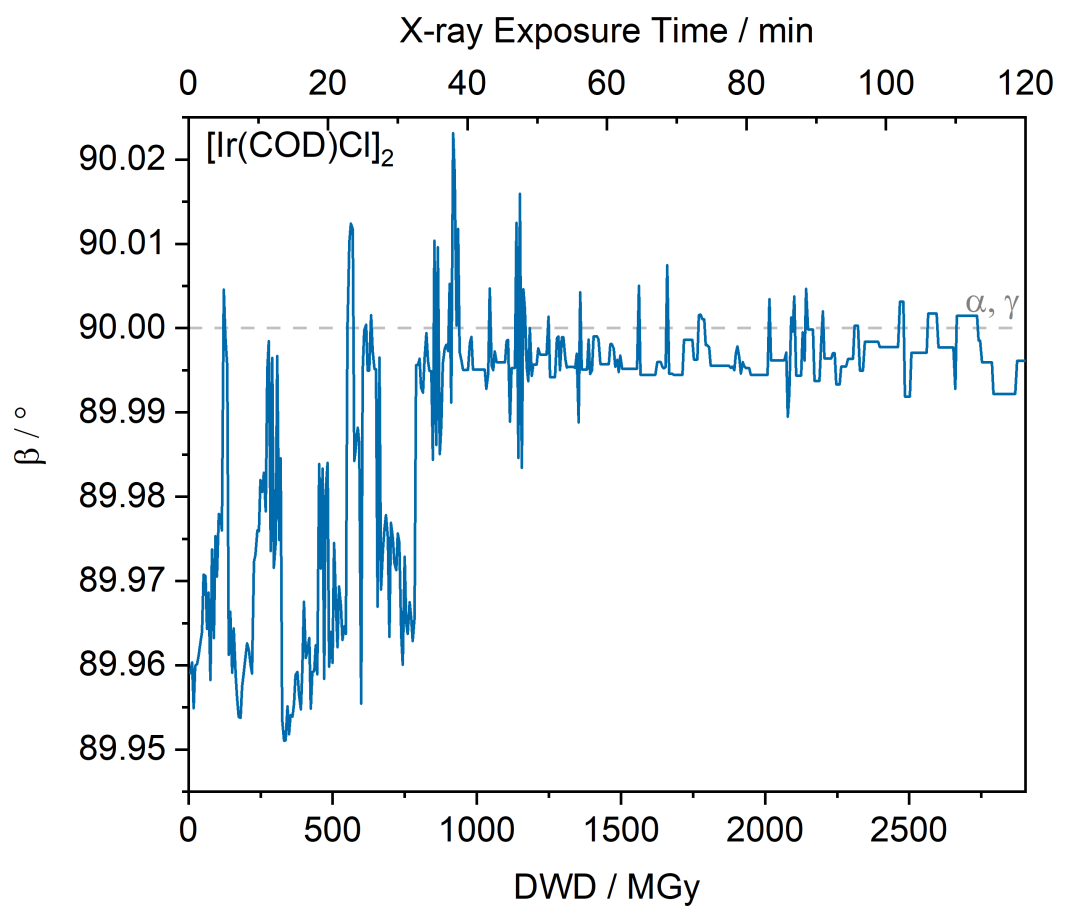

Figure S10: The change in the $\beta$ lattice parameter for $[\operatorname{Ir}(\mathrm{COD}) \mathrm{Cl}]_{2}$ as a function of increasing absorbed dose up to $2903 \mathrm{MGy}$, corresponding to an irradiation time of $2 \mathrm{~h}$. 


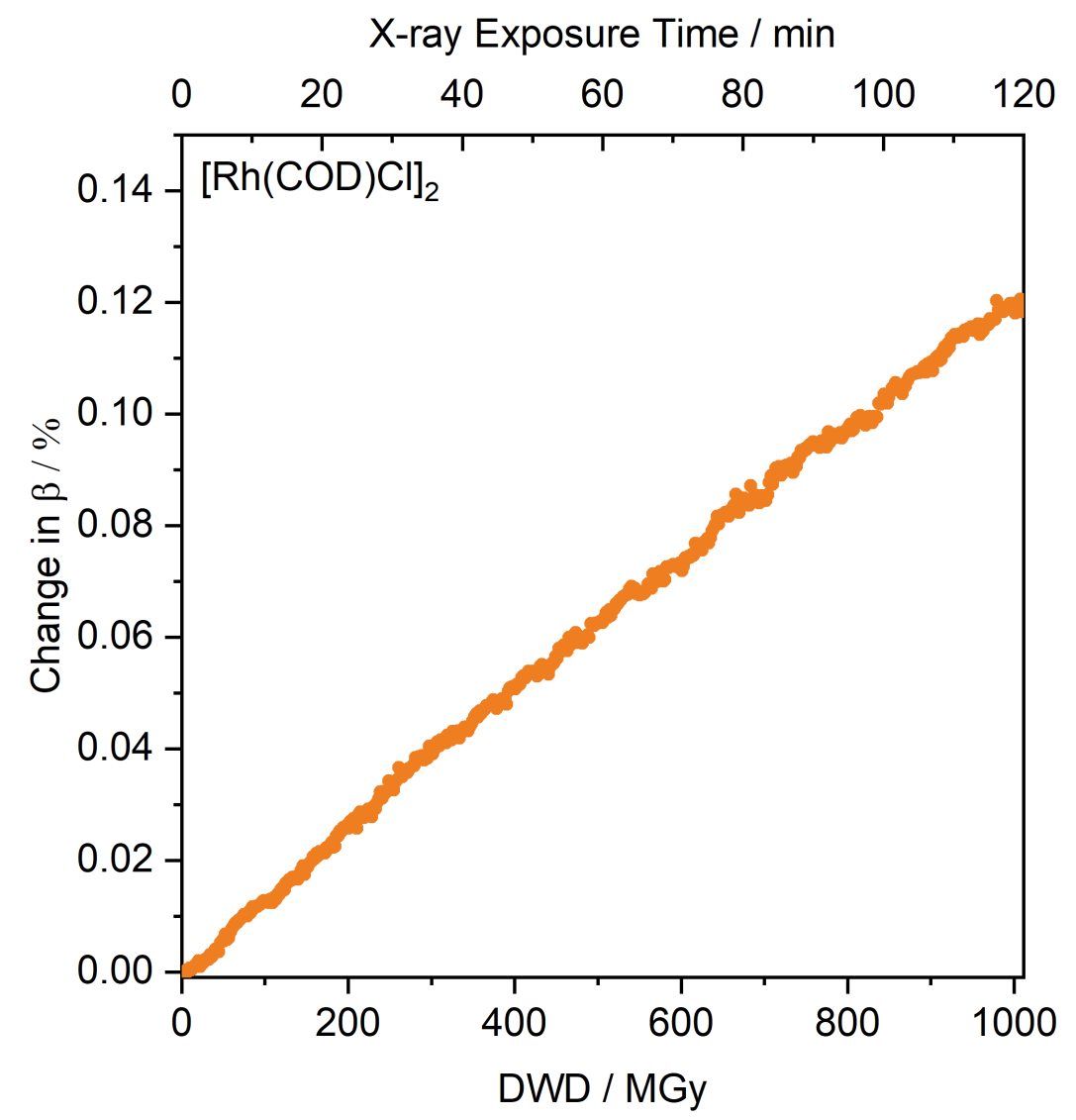

Figure S11: The change in the $\beta$ lattice parameter for $[\mathrm{Rh}(\mathrm{COD}) \mathrm{Cl}]_{2}$ as a function of increasing absorbed dose up to 1012 MGy, corresponding to an irradiation time of $2 \mathrm{~h}$. 


\section{X-ray Photoelectron Spectroscopy}
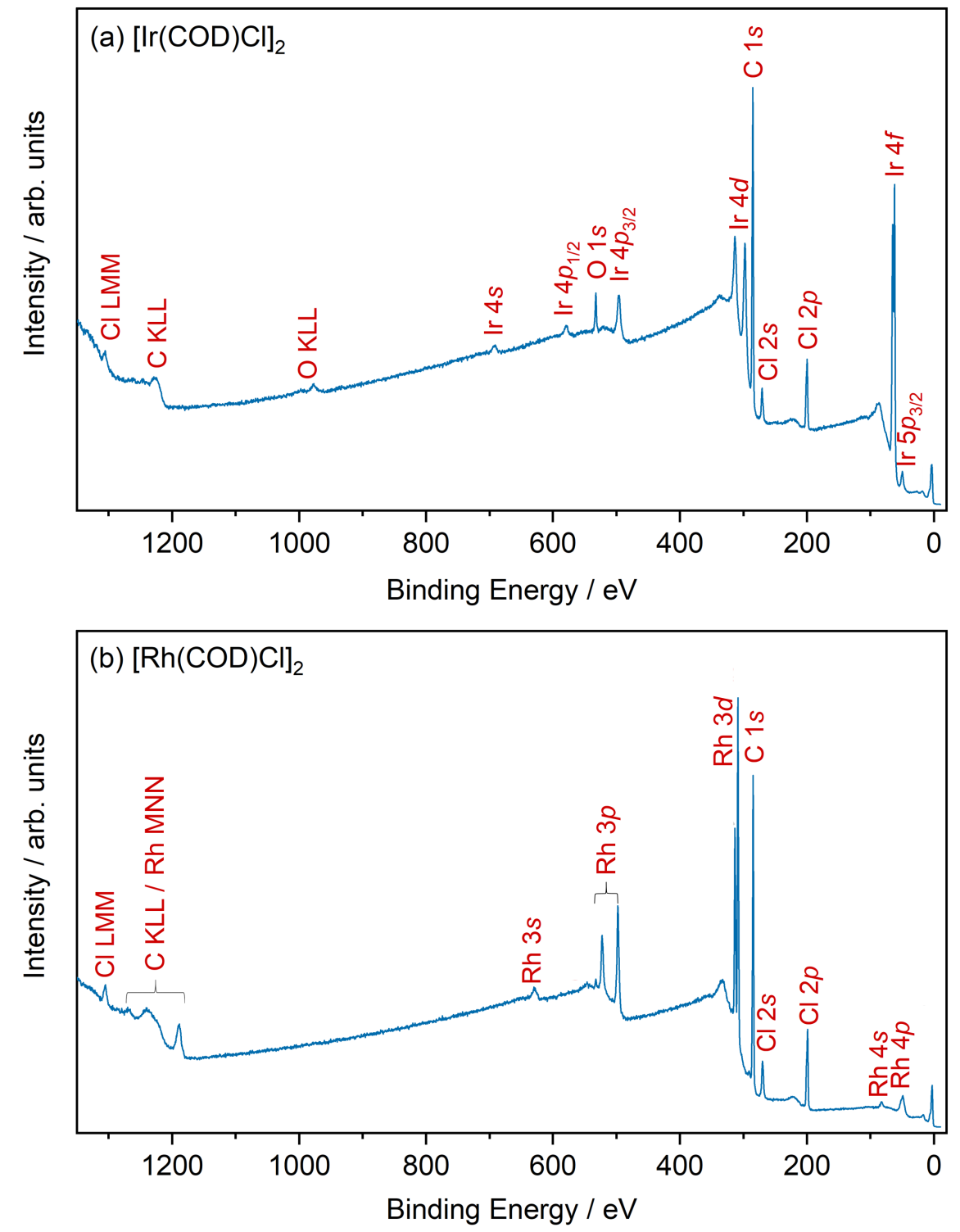

Figure S12: XPS survey spectra of (a) $[\mathrm{Ir}(\mathrm{COD}) \mathrm{Cl}]_{2}$ and $(\mathrm{b})[\mathrm{Rh}(\mathrm{COD}) \mathrm{Cl}]_{2}$. All major core levels and Auger lines are indicated. 

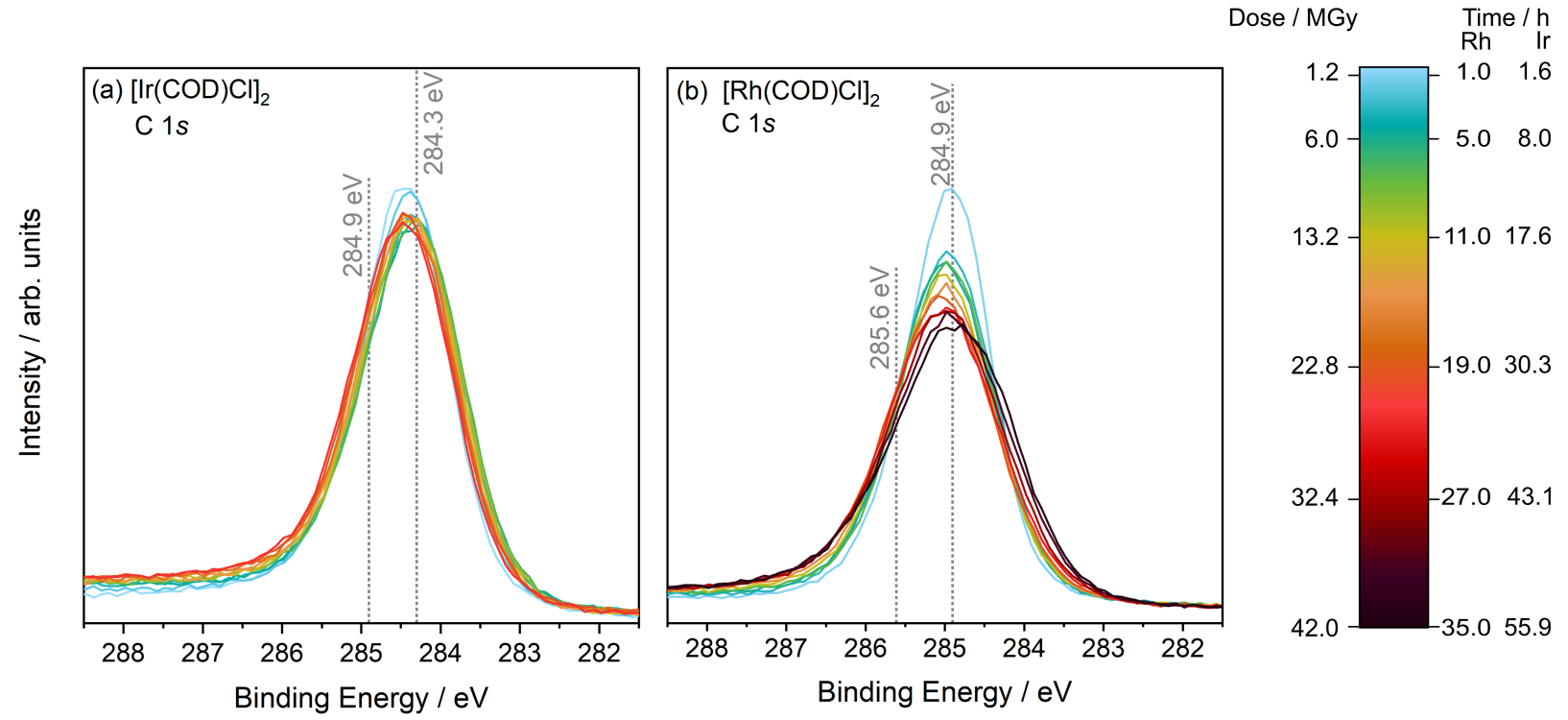

Figure S13: C $1 s$ core level photoelectron spectra over all 18 measurement iterations of (a) $[\operatorname{Ir}(\mathrm{COD}) \mathrm{Cl}]_{2}$ and $(\mathrm{b})[\mathrm{Rh}(\mathrm{COD}) \mathrm{Cl}]_{2}$. The legend denotes the X-ray exposure time and estimated ADWC dose for each complex.
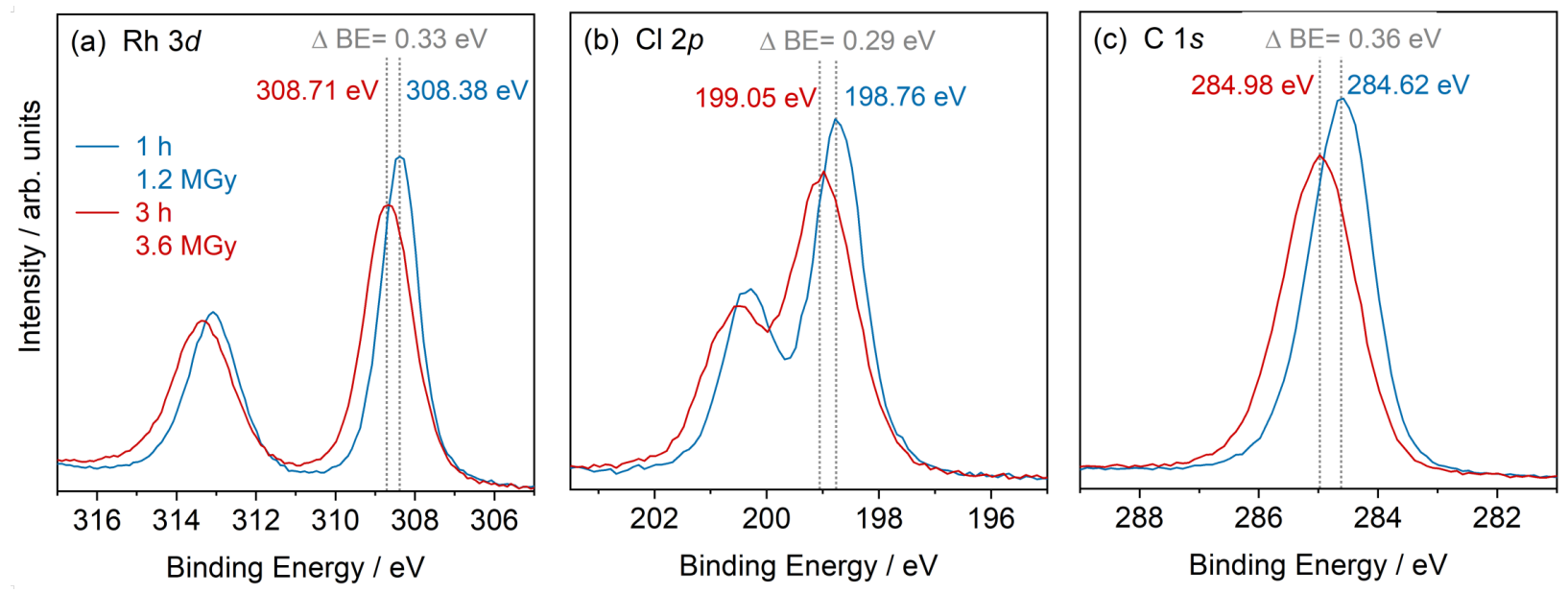

Figure S14: X-ray photoelectron core-level spectra of $[\mathrm{Rh}(\mathrm{COD}) \mathrm{Cl}]_{2}$, including (a) $\mathrm{Rh} 3 d$, (b) $\mathrm{Cl} 2 p$, and (c) $\mathrm{C} 1 s$ at a dose of $1.2 \mathrm{MGy}(\mathrm{t}=1 \mathrm{~h})$ and $3.6 \mathrm{MGy}(\mathrm{t}=3 \mathrm{~h}$ ), showing the consistent systematic shift of the first spectra approximately $0.3 \mathrm{eV}$ towards lower binding energies. All 1.2 MGy dose $(\mathrm{t}=1 \mathrm{~h})[\mathrm{Rh}(\mathrm{COD}) \mathrm{Cl}]_{2}$ spectra included in this study have therefore been shifted by $+0.3 \mathrm{eV}$ to aid comparison. 

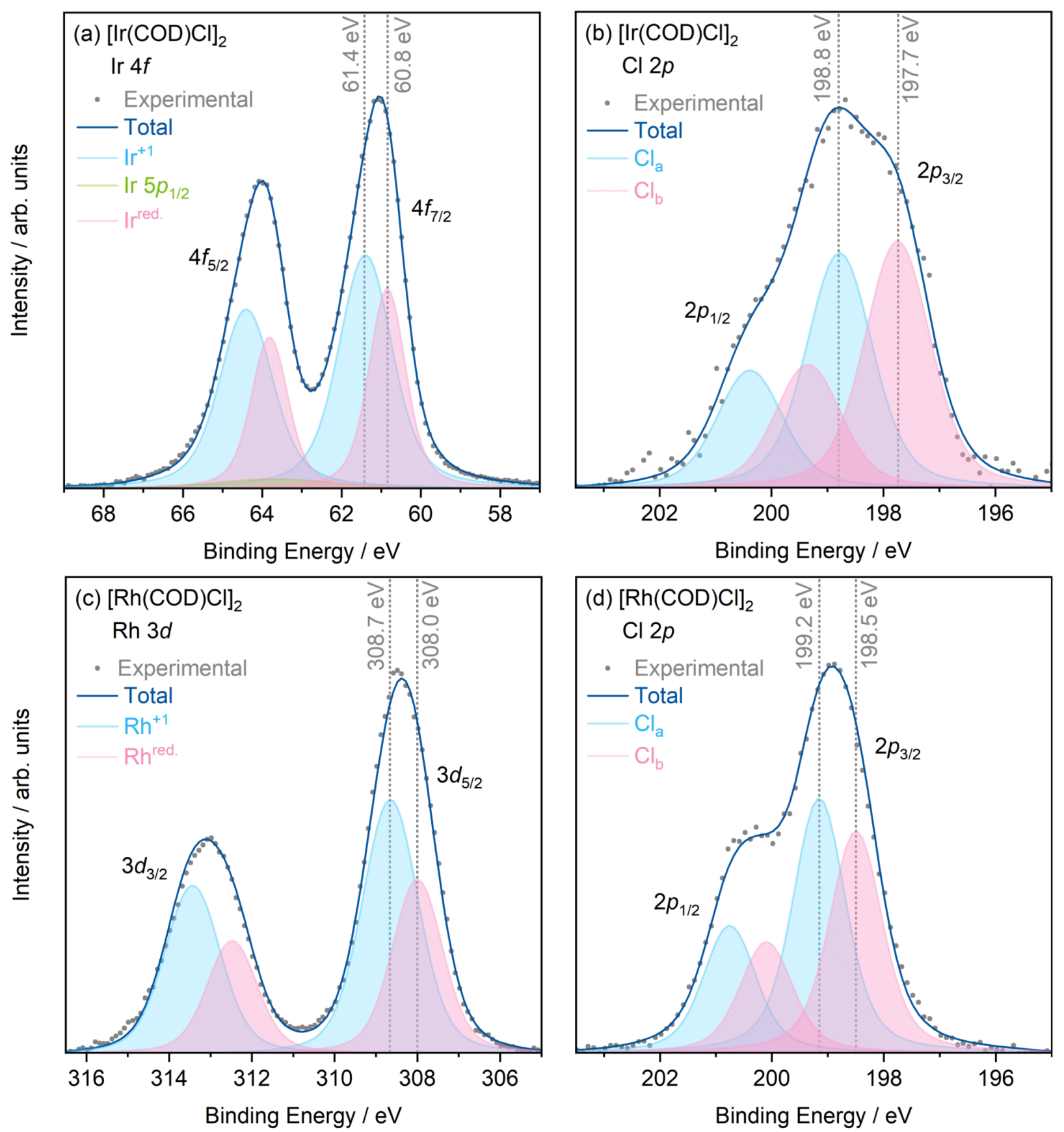

Figure S15: Peak fit analysis of X-ray photoelectron core level spectra at an average dose of 15.8 MGy, including (a) Ir $4 f$, (b) $\mathrm{Cl} 2 p$ for $\left[\operatorname{Ir}(\mathrm{COD}) \mathrm{Cl}_{2}\right.$, and (c) $\mathrm{Rh} 3 d$ and (c) $\mathrm{Cl} 2 p$ for $[\mathrm{Rh}(\mathrm{COD}) \mathrm{Cl}]_{2}$. 

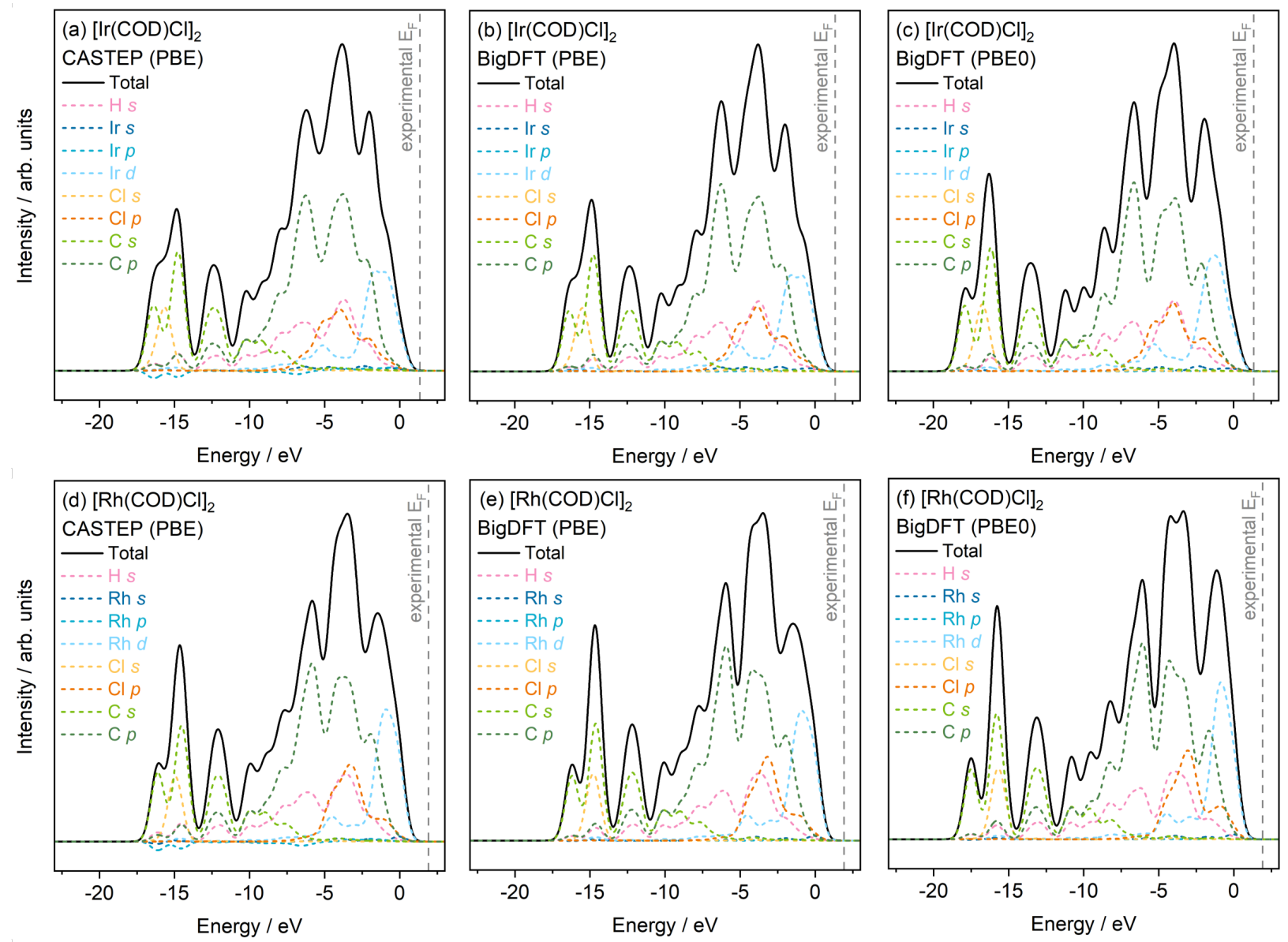

Figure S16: Unweighted total (TDOS) and projected (PDOS) density of states from density functional theory calculations using the CASTEP code and PBE functional for the solids, and the BigDFT code with PBE and PBE0 functionals for gas phase molecules for (a)-(c) $[\operatorname{Ir}(\mathrm{COD}) \mathrm{Cl}]_{2}$ and $(\mathrm{d})-(\mathrm{e})[\mathrm{Rh}(\mathrm{COD}) \mathrm{Cl}]_{2}$, respectively. All plots are aligned to the highest occupied molecular orbital (HOMO). 

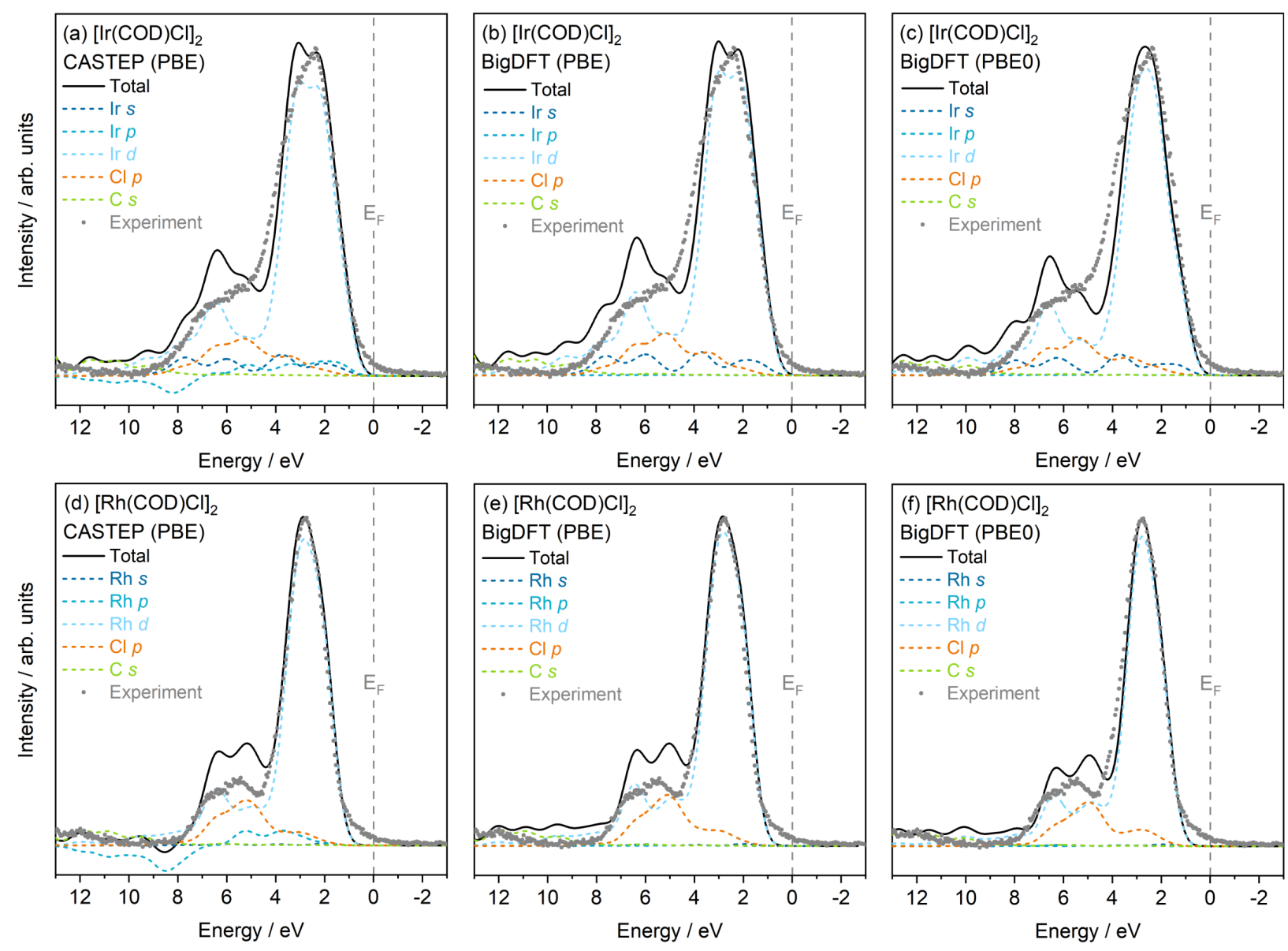

Figure S17: Weighted total (TDOS) and projected (PDOS) density of states from density functional theory calculations using the CASTEP code and PBE functional for the solids, and the BigDFT code with PBE and PBE0 functionals for gas phase molecules for (a)-(c) $[\operatorname{Ir}(\mathrm{COD}) \mathrm{Cl}]_{2}$ and $(\mathrm{d})-(\mathrm{e})\left[\mathrm{Rh}(\mathrm{COD}) \mathrm{Cl}_{2}\right.$, respectively. The theoretical data are aligned to the experimental VBM for comparison. The experimental Fermi energy $E_{F}$ at $0 \mathrm{eV}$ is indicated in all subfigures. Only projected states with significant contributions to the intensity are displayed. 

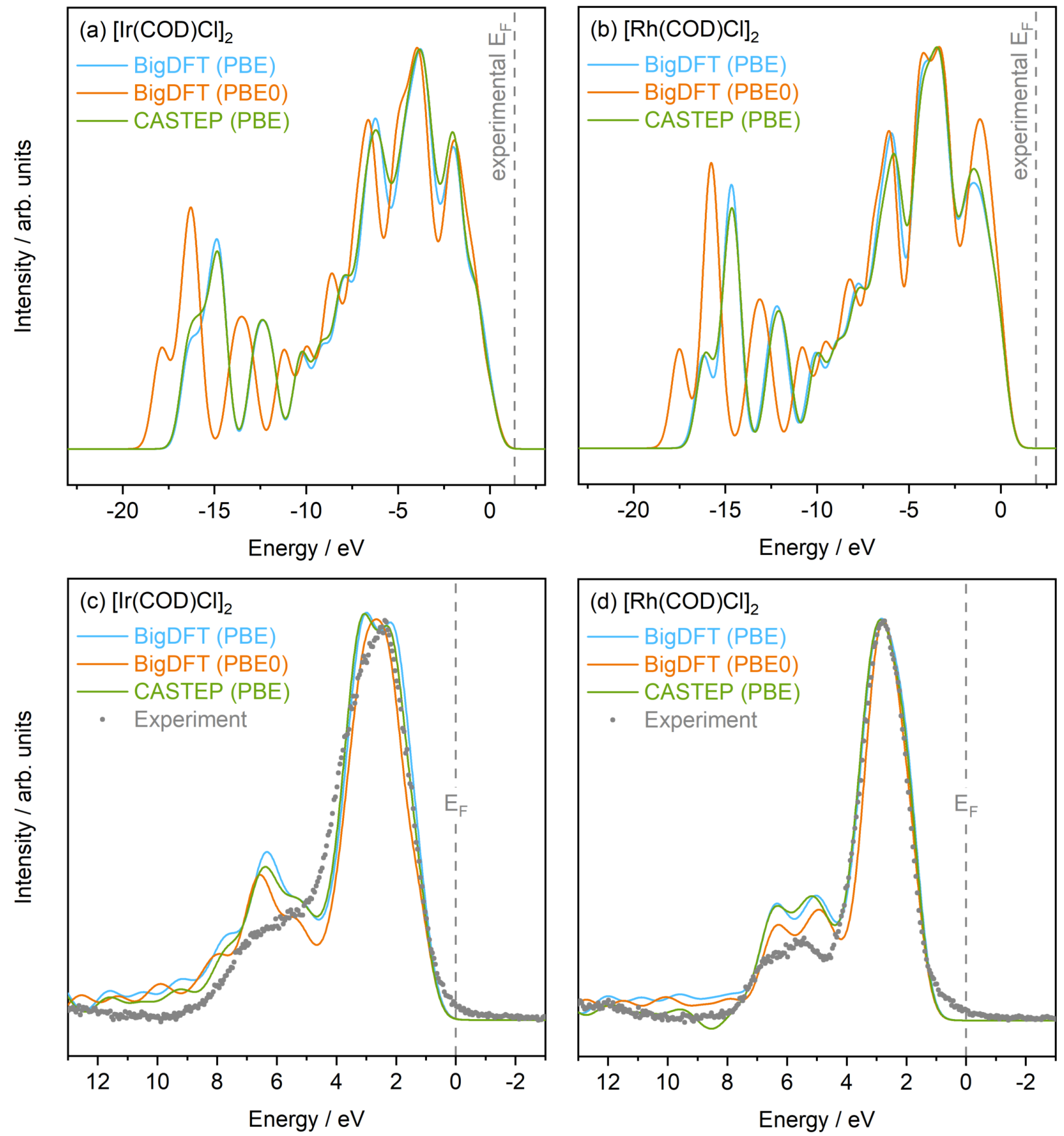

Figure S18: Total densities of states (TDOS), including (a)-(b) unweighted and (c)-(d) weighted TDOS from density functional theory calculations using the CASTEP code and PBE functional for the solids, and the BigDFT code with PBE and PBE0 functionals for gas phase molecules for (a)-(c) $[\mathrm{Ir}(\mathrm{COD}) \mathrm{Cl}]_{2}$ and (d)-(e) $[\mathrm{Rh}(\mathrm{COD}) \mathrm{Cl}]_{2}$, respectively. Plots (c)-(d) also include the experimental data after subtraction of a Shirley-type background. 


\section{X-ray Dose Estimation using RADDOSE-3D}

Table S2: The parameters included in the RADDOSE-3D input file for the small molecule feature used to estimate the doses in the powder XRD experiments at beamline I11 at Diamond Light Source and for the Thermo Scientific K-Alpha+ spectrometer for XPS measurements.

\begin{tabular}{lll}
\hline \hline RADDOSE parameter & $\begin{array}{l}\text { Beamline I11, DLS } \\
(\text { synchrotron PXRD) }\end{array}$ & $\begin{array}{l}\text { K-Alpha+ } \\
(\text { laboratory XPS) }\end{array}$ \\
\hline Crystal type & cylinder & cuboid \\
Crystal Dimension $/ \mu \mathrm{m}$ & $300 \times 40000$ & $60 \times 60 \times 60$ \\
PixelsPerMicron & 0.06 & 0.6 \\
Container material type & mixture & $\mathrm{N} / \mathrm{A}$ \\
Material mixture & pyrex & $\mathrm{N} / \mathrm{A}$ \\
Container thickness $/ \mu \mathrm{m}$ & 10 & $\mathrm{~N} / \mathrm{A}$ \\
Container density $/ \mathrm{g} \mathrm{cm}^{-3}$ & 2.23 & $\mathrm{~N} / \mathrm{A}$ \\
Beam type & Gaussian & Gaussian \\
Photon flux / photons $/ \mathrm{s}$ & $8.62 \times 10^{13}$ & $3.80 \times 10^{10}$ \\
FWHM / $\mu \mathrm{m}$ & $2000 \times 600$ & $326 \times 579$ \\
Energy / keV & 18.05 & 1.487 \\
Collimation type & rectangular & circular \\
Collimation dimensions $/ \mu \mathrm{m}^{2}$ & $2500 \times 800$ & $400 \times 710$ \\
\hline \hline
\end{tabular}

The small molecule feature in RADDOSE-3D was used in this study. this option allows for the full chemical composition of the irradiated crystal to be input, and removes the requirement of the standard MX RADDOSE-3D to enter the solvent atoms present in the unit cell void spaces, which is typically not relevant to standard small molecule crystallography experimental setups. The choice of dose metrics output by the programme used is very much dependent on the experimental setup. Dose absorbed during powder X-ray diffraction experiments was estimated using the Diffraction Weighted Dose (DWD) metric. This metric was determined to be the most appropriate for the diffraction measurements as it considers the dose absorbed during the non-homogeneous irradiation of a sample. Contrary to typical MX experiments, where the X-ray beam irradiates the crystal directly, the powder diffraction experiments conducted here require the samples to be mounted in capillaries, and this must be considered in dose calculations.

Brooks-Bartlett et al. were the first to introduce the computational tools required to 
extend the original RADDOSE-3D capabilities to Small Angle X-ray Scattering (SAXS) experiments. ${ }^{\mathrm{S} 8}$ The authors accounted for the liquid nature of a typical SAXS sample, a cylindrical geometry to more accurately describe the dimensions of the capillary containing the sample, and implemented beam attenuation by the capillary material into the dose calculations. The latter two developments, applicable to transmission powder X-ray diffraction experiments, were used in the dose calculations presented here. To account for the capillary setup in PXRD experiments reported here, the crystal dimensions in the RADDOSE-3D input file is defined as those of the sample-filled capillary. The pixel size is taken to be the approximate size of the individual crystals.

The photon flux of beamline I11 was extracted from a digitised plot of photon flux as a function of photon energy in the work by Thompson et al., as well as the spot size and FWHM. ${ }^{\text {S9 }}$ The goniometer axis parameter in the input file was set to $90^{\circ}$. The properties of the borosilicate glass capillary are taken into account in the I11 dose calculations. For XPS dose estimations, the spot size of the K-Alpha+ instrument was determined with a phosphorescent sample using the Spot Analysis tool on Thermo Scientific's Avantage software, and photon flux information was acquired directly from the supplier.

\section{References}

(S1) Dolomanov, O. V.; Bourhis, L. J.; Gildea, R. J.; Howard, J. A. K.; Puschmann, H. OLEX2 : A Complete Structure Solution, Refinement and Analysis Program. J. Appl. Crystallogr. 2009, 42, 339-341.

(S2) Bourhis, L. J.; Dolomanov, O. V.; Gildea, R. J.; Howard, J. A. K.; Puschmann, H. The Anatomy of a Comprehensive Constrained, Restrained Refinement Program for the Modern Computing Environment - Olex2 Dissected. Acta Crystallogr. A 2015, 71, $59-75$.

(S3) Groom, C. R.; Bruno, I. J.; Lightfoot, M. P.; Ward, S. C. The Cambridge Structural 
Database. Acta Crystallographica 2016, B72, 171-179.

(S4) Pannetier, G.; Tabrizi, D. Etude Radiocristallographique du di- $\mu$-chloro-bis $(\pi$ cyclooctadiène-1,5) Diiridium $[(\mathrm{COD}-1,5) \operatorname{lrCl}]_{2}$, variété Orthorhombique (rougerubis). J. Less Common Met. 1971, 23, 110-112.

(S5) Cotton, F. A.; Lahuerta, P.; Sanau, M.; Schwotzer, W. Air Oxidation of $\operatorname{Ir}_{2}(\mathrm{Cl})_{2}(\mathrm{COD})_{2}$ Revisited. The Structures of $\left[\operatorname{Ir}\left(\mu_{2}-\mathrm{Cl}\right)(\mathrm{COD})\right]_{2}$ (ruby form) and its Oxidation Product, $\mathrm{Ir}_{2} \mathrm{Cl}_{2}(\mathrm{COD})_{2}\left(\mu_{2}-\mathrm{OH}\right)_{2}\left(\mu_{2}-\mathrm{O}\right)$. Inorg. Chim. Acta 1986, 120, 153-157.

(S6) Hill, T. N. CCDC 1477153: CSD Communication. 2016; doi: 10.5517/ccdc.csd.cc1ll33d.

(S7) Zavalij, P. Y.; Stevens, L. M.; Eichhorn, B. W. CCDC 1920502: CSD Communication. 2019; doi: 10.5517/ccdc.csd.cc22gfpp.

(S8) Brooks-Bartlett, J. C.; Batters, R. A.; Bury, C. S.; Lowe, E. D.; Ginn, H. M.; Round, A.; Garman, E. F. Development of Tools to Automate Quantitative Analysis of Radiation Damage in SAXS Experiments. J. Synchrotron Radiat. 2017, 24, 63-72.

(S9) Thompson, S. P.; Parker, J. E.; Potter, J.; Hill, T. P.; Birt, A.; Cobb, T. M.; Yuan, F.; Tang, C. C. Beamline I11 at Diamond: A New Instrument for High Resolution Powder Diffraction. Rev. Sci. Instrum 2009, 80, 075107. 